Article

\title{
Morphology, Crystallinity, and Molecular Weight of Poly( $\varepsilon$-caprolactone)/Graphene Oxide Hybrids
}

\author{
Isabel Castilla-Cortázar ${ }^{1}\left(\mathbb{D}\right.$, Ana Vidaurre ${ }^{1,2}$, Bernabé Marí ${ }^{3}$ and Alberto J. Campillo-Fernández ${ }^{1, *(D)}$ \\ 1 Centro de Biomateriales e Ingeniería Tisular, Universitat Politècnica de València, 46022 Valencia, Spain \\ 2 CIBER de Bioingeniería, Biomateriales y Nanomedicina (CIBER-BBN), 46022 Valencia, Spain \\ 3 Departamento de Física Aplicada-IDF, Universitat Politècnica de València, 46022 Valencia, Spain \\ * Correspondence: alcamfer@ter.upv.es
}

Received: 31 May 2019; Accepted: 21 June 2019; Published: 28 June 2019

check for updates

\begin{abstract}
A study was carried out to determine the effects of graphene oxide (GO) filler on the properties of poly( $\varepsilon$-caprolactone) (PCL) films. A series of nanocomposites were prepared, incorporating different graphene oxide filler contents $(0.1,0.2$, and $0.5 \mathrm{wt} \%)$ by the solution mixing method, and an in-depth study was made of the morphological changes, crystallization, infrared absorbance, molecular weight, thermal properties, and biocompatibility as a function of GO content to determine their suitability for use in biomedical applications. The infrared absorbance showed the existence of intermolecular hydrogen bonds between the PCL's carbonyl groups and the GO's hydrogen-donating groups, which is in line with the apparent reduction in molecular weight at higher GO contents, indicated by the results of the gel permeation chromatography (GPC), and the thermal property analysis. Polarized optical microscopy (POM) showed that GO acts as a nucleating point for PCL crystals, increasing crystallinity and crystallization temperature. The biological properties of the composites studied indicate that adding only $0.1 \mathrm{wt} \%$ of GO can improve cellular viability and that the composite shows promise for use in biomedical applications.
\end{abstract}

Keywords: hybrids; polycaprolactone (PCL); graphene oxide (GO); molecular weight; morphology; FT-IR; biocompatibility

\section{Introduction}

GO is made by oxidating graphite to separate the platelets followed by ultrasound stirring [1-4]. It is a form of graphene with functional groups on the surface, such as carboxyl, hydroxyl, and epoxide groups, which can improve its dispersability in organic solvents [5]. As it can establish good interactions with organic polymers it also has enhanced processability [6,7]. The key aspect in obtaining hybrid materials is the proper dispersion of the reinforcement in the matrix, as well as an excellent interaction between the components [5-15]. Different methods have recently been proposed to process $\mathrm{GO}$, including in situ polymerization, melt blending, and solution mixing, to disperse graphenes in polymer matrices [16]. The second of these methods includes adding a dispersing additive, followed by dissolving a matrix polymer in cosolvents and evaporating the solvent or using non-solvent coagulation to recover the composites. Although the particles are more dispersed than in melt processing, the particles may tend to reaggregate while the solvent evaporates. Melt blending's main benefit is that it can synthesize intercalated nanocomposites formed of low or non-polar polymers [6]. 
The different processes are known to produce different nanofiller dispersion levels in the matrix and affect the polymer composite properties in different ways [17,18]. Sonication, or high-speed shearing, together with solution-phase mixing have been proposed to improve its dispersity and make GO more soluble in non-polar solvents [19].

Aliphatic polyesters have attracted a great deal of research interest due to their biodegradability and biocompatibility [20]. Poly(E-caprolactone) (PCL) is fully biodegradable, biocompatible, and nontoxic to living organisms. Due to its rheological properties, almost any polymer processing method can be used to produce a variety of biomaterial applications, such as drug-delivery systems, sutures, wound dressings, fixation devices, and for dentistry and tissue engineering in the form of muscle, bone, cartilage, tendon, blood, nerve, skin, and cardiac tissues [21]. Several studies have prepared a wide range of PCL hybrids with GO or reduced graphene oxide (RGO) and identified their properties. For example, Kai et al. [20] used GO as a filler to enforce PCL and studied its effects on crystallization and mechanical properties. Biocompatible nanofibrous PCL and PCL/GO nanocomposite films have been prepared by electrospinning with varying GO concentrations to study their mechanical properties [22,23]. A series of PCL/GO and PCL/RGO composites with covalently attached GO and RGO have been synthetized to evaluate GO and RGO dispersion in the PCL matrix and its mechanical and electrical properties [24-26]. Other studies found PCL/GO composites to be useful for various biomedical applications $[22,27,28]$. Due to its peculiar atomic arrangements, $G O$ has a strong adsorbing capacity which makes it suitable for use as a gene/drug delivery vehicle $[29,30]$.

Biocompatibility studies have focused on a variety of methods to evaluate the resulting cytotoxic effects. Several authors have studied graphene oxide (GO) biocompatibility in mice in a series of biological assays and obtained significant pathological changes [31]. Jassim et al. studied the mechanisms by which 2D materials can interact with physiological barriers for potential diagnostic and therapeutic use [32]. Graphenes in a polymer matrix can be toxic to mammalian cells [8-11]. Reduced bacterial reproduction has been found on composite surfaces [33-35], which is important for biomaterial implantation procedures, in which infection is frequent [36]. Sydlik et al. found GO to be moderately compatible in vivo in subcutaneous and intraperitoneal tissue sites, an important issue for medical applications with the risk of inflammation due to foreign bodies [37].

In this study, a series of PCL/GO hybrids were prepared while subtly varying graphene oxide content in order to tune their physicochemical properties. Hybrids were produced by mixing and subsequent solvent casting method with dioxane as solvent. Scanning electron microscopy (SEM) and transmission electron microscopy (TEM) were used to study the morphology, molecular weight distribution was analyzed by GPC, the thermal behavior was studied by differential scanning calorimetry (DSC) and thermal gravimetric analyses (TGA). Interactions between PCL and GO and its effects on crystallinity were analyzed through Fourier-transform infrared spectroscopy (FT-IR). Crystal structure was studied by $\mathrm{x}$-ray diffraction (XRD), and spherulite growth was assessed by POM. Finally, L-929 mouse fibroblasts were used to evaluate in vitro cell compatibility.

\section{Experimental}

\subsection{Materials}

Poly(caprolactone)(PCL) pellets Sigma-Aldrich $\left(M_{\mathrm{w}}=70,000-90,000\right)$ were used without further purification. Dioxane solvent from Fisher and powdered graphene oxide from Graphenea were used as received.

\subsection{Methods}

\subsubsection{Sample Preparation}

PCL/GO samples were prepared by solution mixing and subsequent solvent evaporation as follows: PCL was dissolved in dioxane and mixed with three solutions containing different amounts of GO 
dispersed in dioxane by ultrasound for $20 \mathrm{~min}$ (VWR Ultrasonic Bath USC600TH, VWR International, Leuven, Belgium). The resulting mixtures $(0.1,0.2$, and $0.5 \% w / w \mathrm{GO} / \mathrm{PCL})$ were mechanically stirred and returned to the ultrasound bath for $4 \mathrm{~h}$. After sounding, the samples were placed under a vacuum pump in continuous extraction for $30 \mathrm{~min}$ at $40{ }^{\circ} \mathrm{C}$ to eliminate bubbles and left under vacuum for seven days to completely remove the solvent. The films were labeled according to GO content $(\mathrm{wt} \%)$ as follows: PCL (neat PCL), PCL/GO-0.1 (0.1 wt \% of GO), PCL/GO-0.2 (0.2 wt\% GO), and PCL/GO-0.5 ( $0.5 \mathrm{wt} \%$ GO). The mean thickness of all the films was $2 \mathrm{~mm}$. A balance (Mettler Toledo) with a sensitivity of $0.01 \mathrm{mg}$ was used to weigh the samples.

\subsubsection{Morphology: SEM and TEM}

SEM pictures of samples were taken by a JEOL JSM-5410 (Tokyo, Japan) scanning electron microscope to study the surface and cross section morphology of the dried samples after previous sputter-coating with gold at $10 \mathrm{kV}$ of acceleration voltage and $15 \mathrm{~mm}$ working distance. For the TEM observations sample slices were obtained with a cryogenic Leica EM UC7 (Wetzlar, Germany) ultramicrotome equipped with the Leica EM FC7 low temperature sectioning system. Samples were sectioned with a DIATOME diamond knife at around $-70{ }^{\circ} \mathrm{C}$ and mounted on a copper grid. Images were taken by a JEOL JEM-1010 transmission electron microscope at $100 \mathrm{kV}$.

\subsubsection{FT-IR Analysis}

In this study the spectra were obtained from 64 scans taken at a rate of 1 scan/second at ambient temperature by means of an ALPHA FT-IR Spectrometer (Bruker, Ettlingen, Germany) in the wavenumber range of $400-4000 \mathrm{~cm}^{-1}$. Measurements were obtained by attenuated total reflectance spectroscopy (ATR, Bruker, Ettlingen, Germany) with a Platinum ATR single reflection diamond ATR accessory.

\subsubsection{POM}

POM was applied to directly observe the crystallization of neat PCL and the hybrids. Thin films were obtained by dissolving each sample in TetraHydroFuran (THF) $(2 \% w / w)$ and subsequent solvent evaporation on a cover microscope slide. The samples were subjected to thermal treatment with a Linkam THMS600 (Waterfield, UK) hot stage mounted on a polarized light microscope (NIKON Eclipse E600, Tokyo, Japan) and equipped with a TP93 control unit. The samples were heated to $80^{\circ} \mathrm{C}$ followed by cooling to $40{ }^{\circ} \mathrm{C}$ at $40{ }^{\circ} \mathrm{C} \cdot \mathrm{min}^{-1}$ and maintained at this temperature to allow crystallization, which was monitored by a video camera connected to a computer.

\subsubsection{GPC}

The sample weight average molar mass was measured by gel permeation chromatographer at $35^{\circ} \mathrm{C}$ by a Waters Breeze GPC system with a 1525 Binary HPLC pump (Waters Corporation, Milford, MA, USA), a 2414 Refractive Index Detector and Styragel HR THF columns. THF eluent was applied at a flow rate of $1 \mathrm{~mL} \cdot \mathrm{min}^{-1}$. Shodex monodisperse polystyrene standards (Showa Denko K.K. Kawasaki, Japan) were used to obtain the calibration curve.

\subsubsection{Atomic Force Microscopy (AFM)}

AFM was carried out on a Bruker MultiMode 8 SPM (Billerica, MA, USA) in tapping mode in air on a NanoScope V Controller and NanoScope Version 8.15 software and an antimony (n) doped silicon cantilever (Bruker) with a nominal force constant of $3 \mathrm{~N} \cdot \mathrm{m}^{-1}$ and resonance frequency of $75 \mathrm{kHz}$. The phase signal at the tip resonance frequency was zero, with a tapping frequency between $5 \%$ and $10 \%$ below the resonance frequency, drive amplitude of $270 \mathrm{mV}$ and amplitude setpoint of $600 \mathrm{mV}$, with the amplitude setpoint/free amplitude ratio at 0.83 . 


\subsubsection{DSC}

The sample thermal properties were determined in triplicate on an indium-calibrated Mettler Toledo differential scanning calorimeter (DSC, Perkin Elmer, Überlingen, Germany), with an initial heating scan of -10 to $100^{\circ} \mathrm{C}$, a cooling scan of 100 to $-10^{\circ} \mathrm{C}$ and another heating scan of -10 to $100^{\circ} \mathrm{C}$ at a scan rate of $10^{\circ} \mathrm{C} / \mathrm{min}$. Crystallinity was assumed to be proportional to the experimental heat of fusion of $139.5 \mathrm{~J} \cdot \mathrm{g}^{-1}$ for the $100 \%$ crystalline PCL, according to [38].

\subsubsection{XRD}

The PCL/GO samples' X-ray diffraction spectra were taken on a Rigaku Ultima IV X-ray diffractometer in the Bragg-Bentano configuration with the $\mathrm{K} \alpha$ radiation of a $\mathrm{Cu}$ anode from $2 \theta=5^{\circ}-35^{\circ}$ at a speed of $2^{\circ} \cdot \mathrm{min}^{-1}$. The Debye-Scherrer equation [39].

$$
D=0.9 \frac{\lambda}{\beta \cos \theta}
$$

where $\mathrm{D}$ is apparent particle size, $\beta$ the full-width at half-maximum (FWHM) of the x-ray diffraction line (additional peak broadening) in radians, $\lambda$ the wavelength, and $\theta$ is the angle between the incident ray and the scattering planes. In Equation (1) the 0.9 constant is partially dependent on the degree of crystal symmetry, as other research groups have found $[40,41]$.

\subsubsection{TGA}

Three replicates of approximately $4 \mathrm{mg}$ samples were subjected to thermogravimetric analyses (TGA) on a TGA/DSC 2 STAR System (Mettler Toledo, Columbus, OH, USA) thermobalance, at $10^{\circ} \mathrm{C} \cdot \mathrm{min}^{-1}$ from 30 to $1000{ }^{\circ} \mathrm{C}$ in a nitrogen atmosphere of $50 \mathrm{~mL} \cdot \mathrm{min}^{-1}$ to obtain inorganic content and thermal decomposition profiles.

\subsubsection{Cell Culture and Statistical Analysis}

PCL, PCL/GO hybrids and latex (positive control) were sanitized by soaking the surfaces with pure ethanol (Sharlab, Barcelona, Spain) for $1 \mathrm{~h}$, ethanol $70 \%$ for $1 \mathrm{~h}$, ethanol $50 \%$ for $10 \mathrm{~min}$, ethanol $30 \%$ for 10 min and washed 3 times with Dulbecco's phosphate-buffered saline (DPBS) without $\mathrm{Ca}^{2+}$ and $\mathrm{Mg}^{2+}$ (Thermofisher, Madrid, Spain). $0.4 \mathrm{~g}$ of the sanitized materials were soaked in $2 \mathrm{~mL}$ of Dulbecco's modified eagle medium (DMEM) (Gibco) $4.5 \mathrm{~g} \cdot \mathrm{L}^{-1}$, glucose supplemented with $10 \% v / v$ fetal bovine serum (FBS) (Life Technologies SA), and $1 \% v / v$ penicillin/streptomycin $(100 \mathrm{U} / \mathrm{mL} / 100 \mathrm{mg} / \mathrm{mL})$ at $37^{\circ} \mathrm{C}$ in $5 \% \mathrm{CO}_{2}$ atmosphere for $24 \mathrm{~h}$, hereinafter known as the extraction medium.

Mouse fibroblasts L929 (Sigma-Aldrich Quimica SL, Madrid, Spain), passage 16, were seeded on a 96 treated-multiwell plate. Then, $10^{4}$ cells/well were cultured in the medium described above for $3 \mathrm{~h}$ to allow the cells to attach to the bottom surface. The medium was replaced by the extraction medium and the cells were incubated at $37^{\circ} \mathrm{C}$ in a $5 \% \mathrm{CO}_{2}$ atmosphere for $48 \mathrm{~h}$. Treated-polystyrene wells were used as negative control.

Cell vitality was evaluated by replacing the extraction medium by a solution of DMEM without phenol-red with $10 \%$ of methylthiazolyldiphenyl-tetrazolium bromide (MTT) and incubated at $37^{\circ} \mathrm{C}$ in $5 \% \mathrm{CO}_{2}$ for $2.5 \mathrm{~h}$. The cells were then washed twice with DPBS without $\mathrm{Ca}^{2+}$ and $\mathrm{Mg}^{2+}$ (Sigma-Aldrich) and a solubilization solution of isopropanol (Sigma-Aldrich), $0.1 \% v / v$ Nonidet P 40 Substitute (Sigma-Aldrich), and $4 \mathrm{mM} \mathrm{HCl}$ (Sharlab) for $30 \mathrm{~min}$ in an orbital shaker to break the cell membranes and extract the formazan crystals. Spectrophotometric quantification at a wavelength of $570 \mathrm{~nm}$ was 
performed on a Victor 31,420 Multilabel counter spectrophotometer (Perkin Elmer, Turku, Finland). The mean value and statistical deviation of the obtained absorbance were obtained from six replicates after subtracting the mean value of the blank (without cells). The nonparametric Kruskal-Wallis test was applied to the materials, plus a post hoc Mann-Whitney U-test on paired groups if significant differences were found.

\section{Results and Discussion}

\subsection{Visual Examination, SEM, and TEM}

Pristine PCL was seen to be white by visual examination, while hybrid samples showed a uniform dark color, which become deeper as GO concentration increased (Figure 1). The microstructure of the surfaces and cross sectional area of the prepared films and their surfaces appeared practically smooth and even when monitored by SEM, with the exception of the PCL/GO-0.5 samples, which had a different structure. These samples had a flat, smooth upper surface, but an inconsistent porous distribution in the matrix, although no pores were visible on their surface. Similar morphological differences have been found elsewhere on opposite faces of PCL films prepared by solvent evaporation [42]. The surface in contact with the glass was found to be rough and had pores forming irregular voids, while the surface open to the air was less porous and smoother.
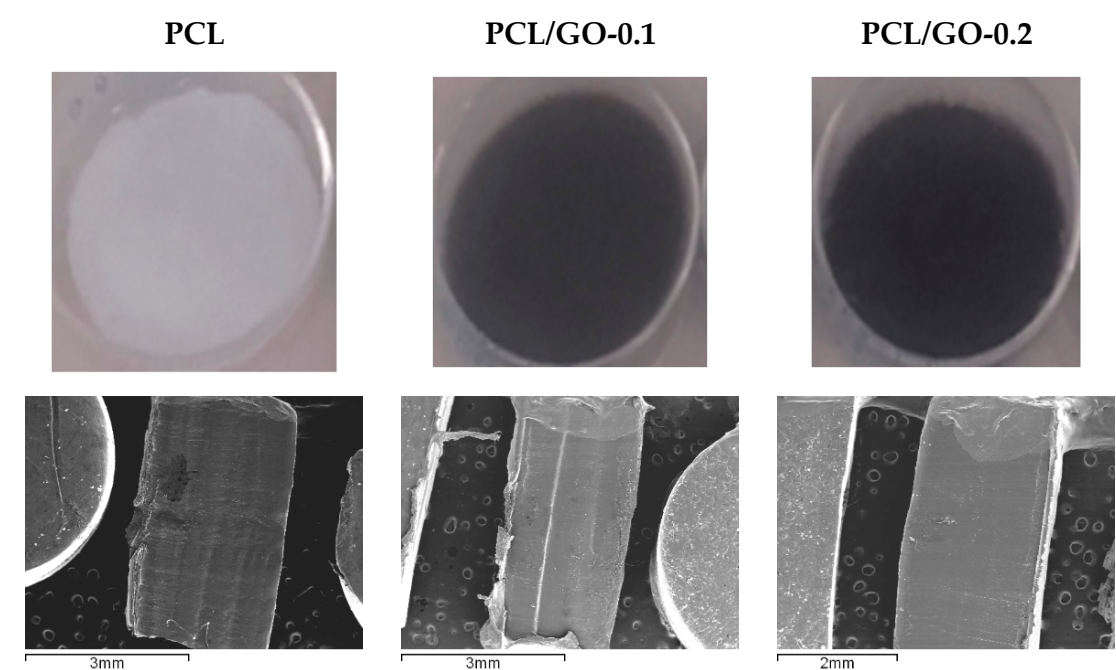

\section{PCL/GO-0.5}
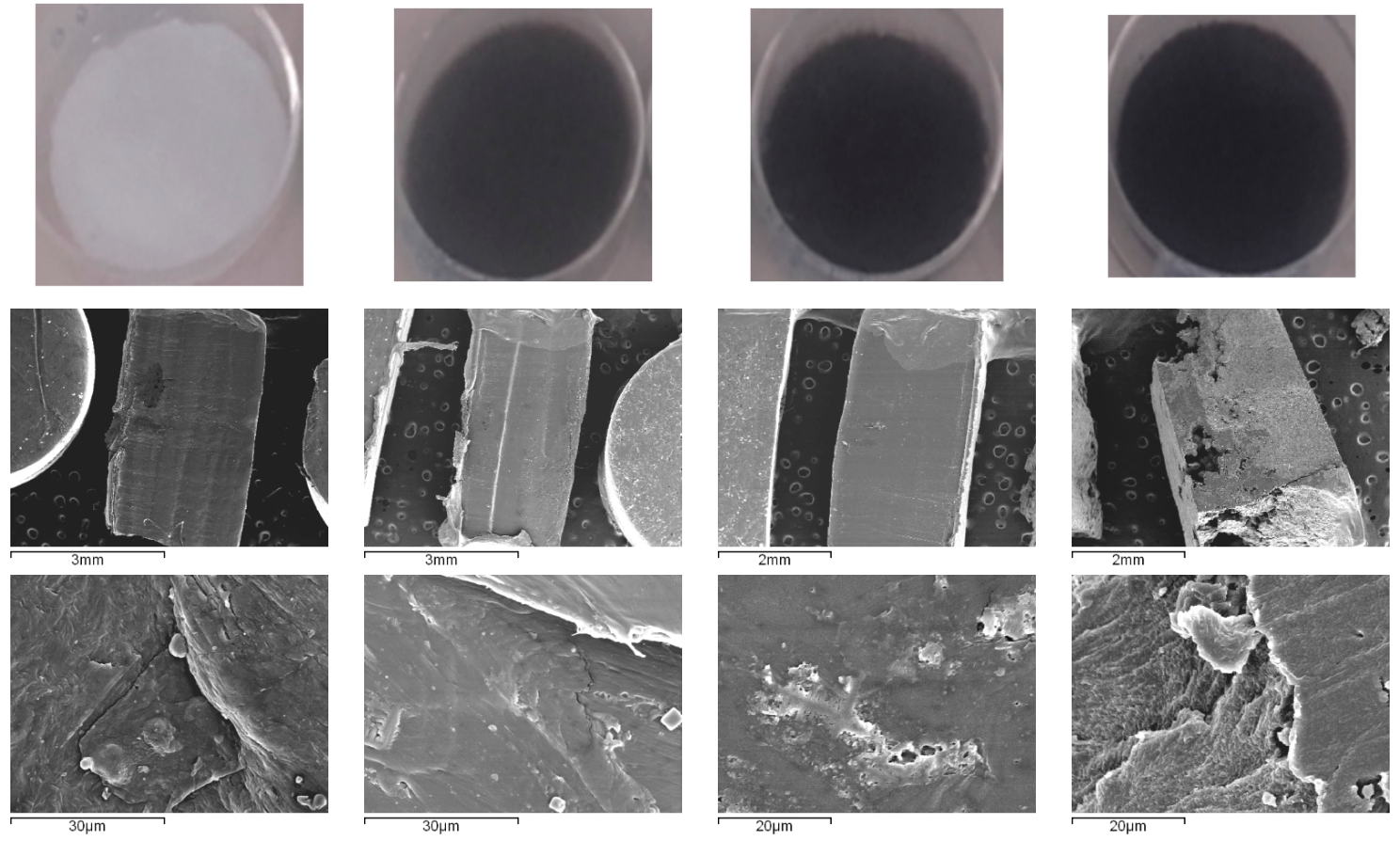

Figure 1. Sample photographs (above) and transversal SEM images according to GO content.

The size dispersion of the GO flakes can be seen in Figure 2a after passing through the ultrasonic bath dispersion process. The largest flake is around 4 microns together with fragments in the order of nanometers. Figure $2 b, c$ show TEM images of the hybrids PCL/GO- 0.2 and PCL/GO-0.5, respectively, where the sheets are seen to be heterogeneously dispersed in the matrix, together with areas with GO aggregates. Figure $2 d$ shows a higher magnification of Figure $2 b$ with GO sheets of different sizes dispersed in the matrix. 

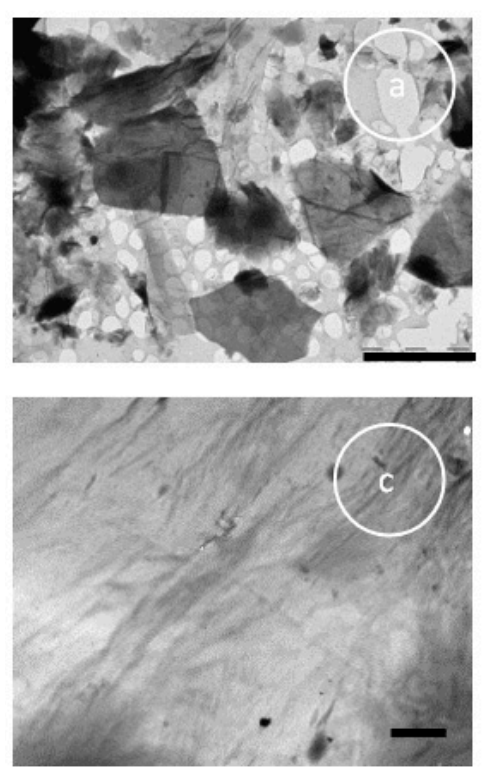

Figure 2. TEM images of GO (a); PCL/GO-0.2 (b); PCL/GO-0.5 (c) and PCL/GO-0.2 at higher magnification (d); Scale bar for (a) represents 5 microns, for (b,c) 2 microns and for (d) $500 \mathrm{~nm}$.

\section{2. $P O M$}

POM images are shown in Figures 3 and 4. The isothermal growth of spherulites at $40{ }^{\circ} \mathrm{C}$ can be observed as a function of time and GO content. Firstly, it should be noted that PCL shows a structure with an average grain size of $~ 0.02 \mathrm{~mm}^{2}$; when $0.1 \mathrm{wt} \%$ GO is added the average grain size decreases sharply, while the trend reverses with higher contents, with larger average size as GO increases, as can be seen in Figure 3. It is worth noting that GO acts as a nucleation point for the spherulites: The red arrows for PCL/GO-0.1 represent GO fragments, which act as nuclei for spherulite growth. At higher contents GO tends to stack with fewer and larger crystals with large defects on the grain boundaries. This could explain the extreme fragility of the PCL/GO-0.5 samples, as they break easily, which is in agreement with the mechanical properties observed in previous studies [23]. Crystallization time (crystals covering the whole frame) was found to diminish with GO content, as shown in Figure 3, from $\sim 50 \mathrm{~min}$ for neat PCL to $\sim 9 \mathrm{~min}$ for PCL/GO-0.5, which seems to obey a negative exponential law. This again can be attributed to the GO acting as a nucleation point. In order to better observe the final structure, Figure 4 shows the spherulites after the crystallization process. The evolution of crystal size with the previously mentioned GO content can be clearly seen.

\subsection{FT-IR}

FT-IR spectra of GO, neat PCL and PCL/GO composites are shown in Figure 5. A prominent characteristic absorption at $1,721 \mathrm{~cm}^{-1}$ for neat PCL and hybrids corresponding to the carbonyl stretching mode can be seen.

Due to the semicrystalline nature of PCL and its composites, spectra were resolved on the basis of three Laurentzian shaped absorption bands with maximum absorbance at 1734, 1721, and $1700 \mathrm{~cm}^{-1}$, which are attributed to carboxyl absorption bands of amorphous phase, crystalline phase, and hydrogen bonds $[22,43,44]$. The peak at $1700 \mathrm{~cm}^{-1}$ was due to hydrogen-bonded carbonyl vibration thought to be caused by the intermolecular hydrogen bonds between the PCL carbonyl groups and GO hydrogen-donating groups [22]. Figure $6 \mathrm{a}, \mathrm{b}$ show the FT-IR spectrum and the fitted curves of the neat PCL and the hybrid PCL/GO-0.5, respectively. For the sake of comparison, numerical results of the normalized intensity of the bands at 1734,1721 and $1700 \mathrm{~cm}^{-1}$ are shown in Table 1 . The peak around $1700 \mathrm{~cm}^{-1}$ increases with GO content, showing the growth of intermolecular hydrogen bonds as GO content increases. It should also be noted that the amorphous peak decreases as the GO content increases. 


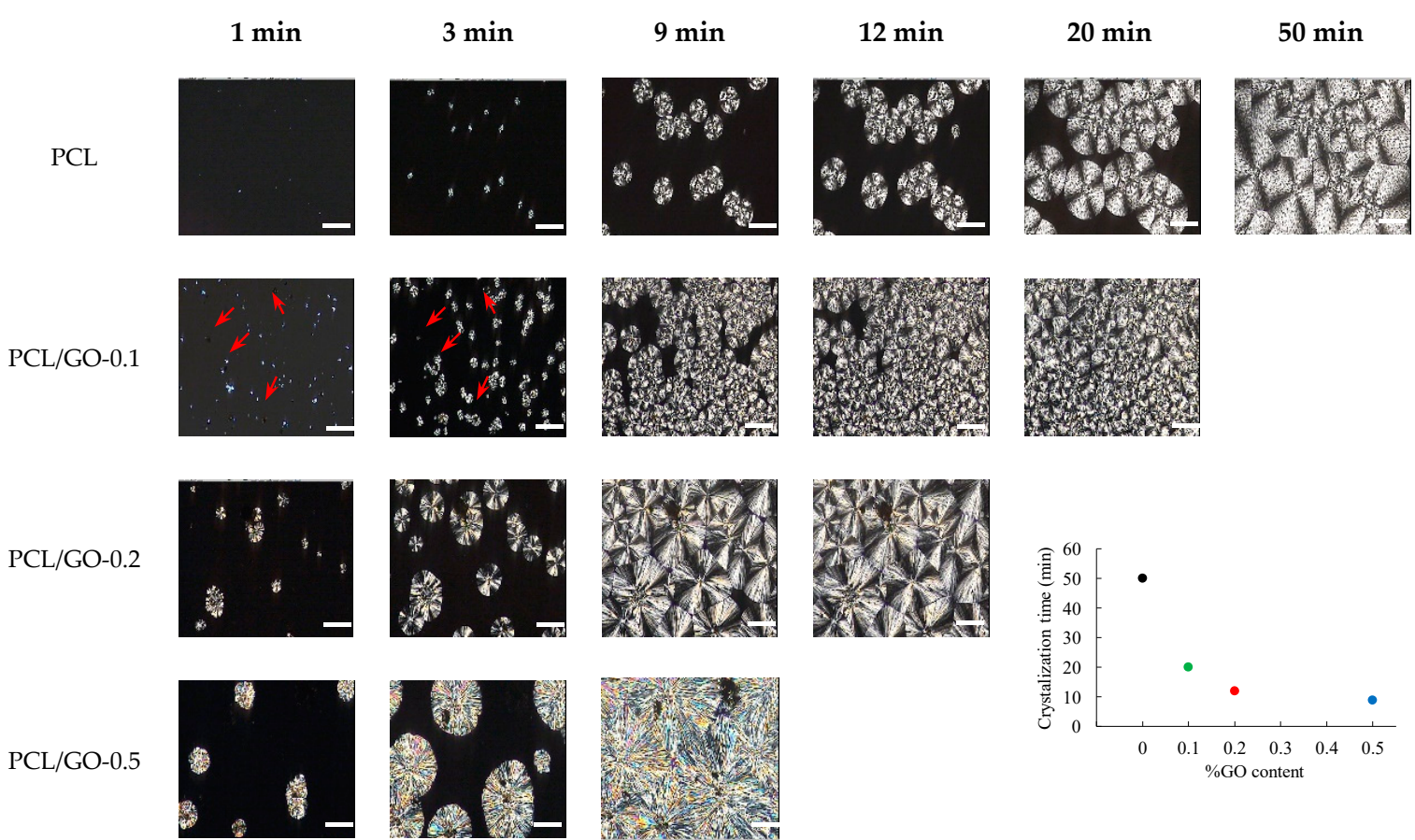

Figure 3. Spherulite growth according to GO content (wt\%). Graph shows the time at which crystallization is completed vs. GO content (wt\%) (white bar represents 100 microns).

PCL

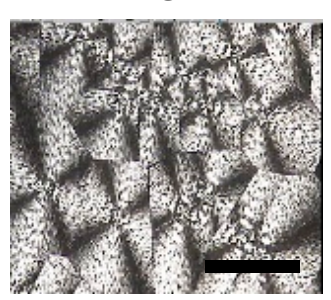

PCL/GO-0.1

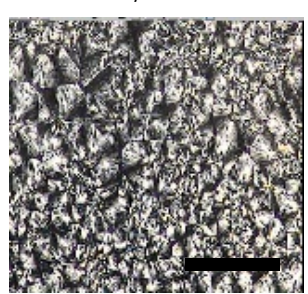

PCL/GO-0.2

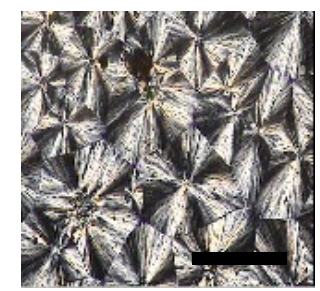

PCL/GO-0.5

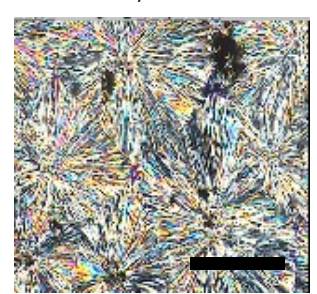

Figure 4. Spherulite final structure according to GO content (wt\%) (black bar represents $200 \mu \mathrm{m})$.

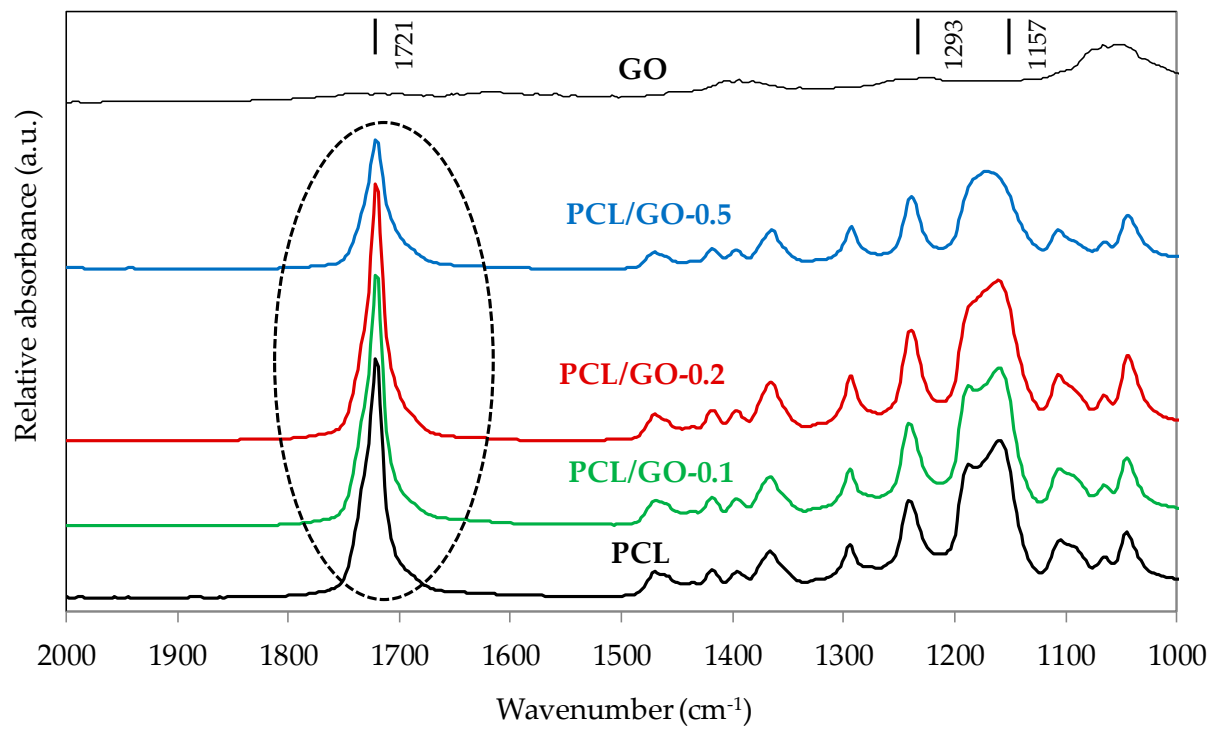

Figure 5. FT-IR spectra of GO, neat PCL and PCL/GO composites. 


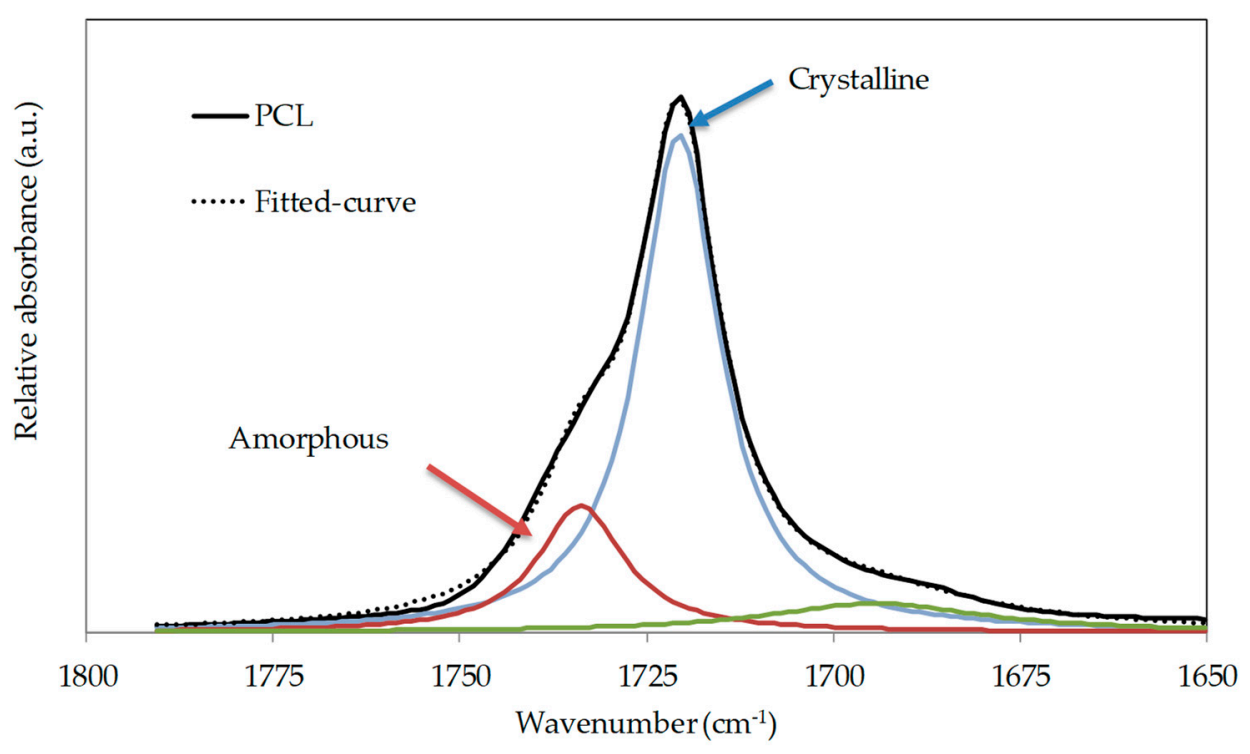

(a)

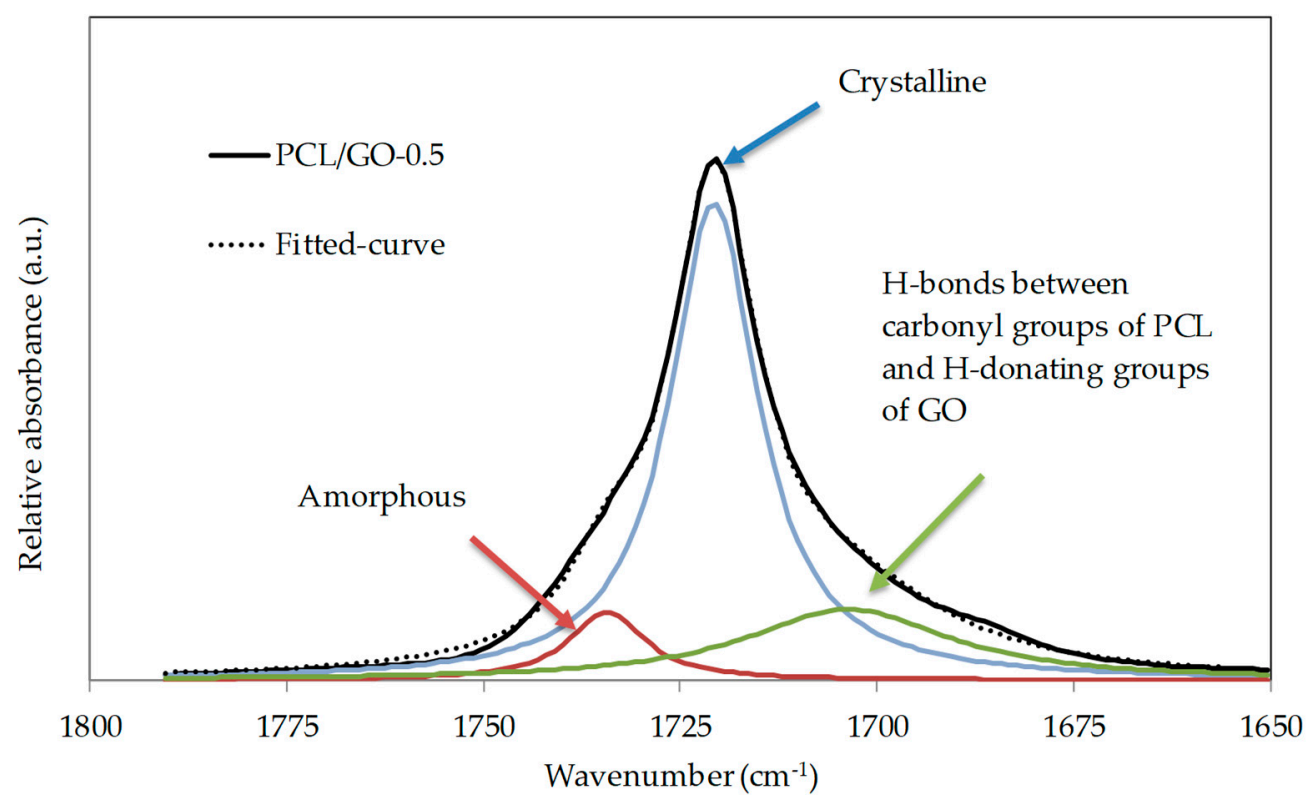

(b)

Figure 6. Experimental and fitted-curve FT-IR spectra of the $\mathrm{C}=\mathrm{O}$ stretching region of (a) PCL (b) PCL/GO-0.5.

Table 1. Normalized intensity of the carboxyl absorption band decomposition at 1734,1721 and $1700 \mathrm{~cm}^{-1}$.

\begin{tabular}{cccc}
\hline Sample & Crystalline & Amorphous & H-Bonding \\
\hline PCL & $76.3 \%$ & $19.3 \%$ & $4.4 \%$ \\
PCL/GO-0.1 & $77.1 \%$ & $18.0 \%$ & $4.8 \%$ \\
PCL/GO-0.2 & $77.4 \%$ & $14.0 \%$ & $8.5 \%$ \\
PCL/GO-0.5 & $77.4 \%$ & $11.1 \%$ & $11.5 \%$ \\
\hline
\end{tabular}

Likewise, the absorption of the $\mathrm{C}-\mathrm{C}$ and $\mathrm{C}-\mathrm{O}$ groups was analyzed in the crystalline and amorphous phases, corresponding to the 1293 and $1157 \mathrm{~cm}^{-1}$ wavelengths, respectively (see Figure 5). It is important to mention that two peaks can be distinguished for neat PCL at 1180 and $1157 \mathrm{~cm}^{-1}$, while three bands are overlapping [45]. Also, as GO content increases these two peaks become a single 
broad peak, indicating the decrease of the amorphous phase Table 2 shows the absorbance intensity at 1293 and $1157 \mathrm{~cm}^{-1}$, where, again, the ratio between the crystalline and amorphous phases increases with GO content.

Table 2. Absorbance intensity of the $\mathrm{C}-\mathrm{C}$ and $\mathrm{C}-\mathrm{O}$ groups in the crystalline and amorphous phase at 1293 and $1160 \mathrm{~cm}^{-1}$.

\begin{tabular}{cccc}
\hline Sample & $\mathbf{1 2 9 3} \mathbf{~ m}^{\mathbf{- 1}}$ Crystalline & $\mathbf{1 1 5 7} \mathbf{~ m}^{-\mathbf{1}}$ Amorphous & Crystalline/Amorphous Ratio \\
\hline PCL & 0.19667 & 0.53359 & $37 \%$ \\
PCL/GO-0.1 & 0.22069 & 0.56913 & $39 \%$ \\
PCL/GO-0.2 & 0.25354 & 0.57757 & $44 \%$ \\
PCL/GO-0.5 & 0.22497 & 0.49367 & $46 \%$ \\
\hline
\end{tabular}

\subsection{GPC}

Figure 7 shows the molecular weight distribution obtained by GPC using the Mark-Houwink-Sakurada parameters provided by Huang et al. [46], $\left(\mathrm{k}=2.9 \cdot 10^{-4}\left(\mathrm{dL} \cdot \mathrm{g}^{-1}\right) \alpha=0.7\right)$. Table 3 gives the weight-average molecular weight, $M_{\mathrm{w}}$, and polydispersity index (PDI) for the samples with different GO contents. As can be seen in Figure $7, M_{\mathrm{w}}$ was unexpectedly found to drop significantly when the GO content was added, although the procedure followed to prepare the samples by solution mixing and solvent evaporation should not affect the PCL molecular weight. In other studies $[24,44,45]$ with polymerization in the presence of GO it has been found that GO reduced the initiator efficiency and the reaction rate, with a slight increase in the average molecular weight of the polymer formed, but this was not the case here. The GPC measurements were repeated with samples of different molecular weights prepared with PCL, and other samples prepared following the same procedure, but with THF instead of dioxane as solvent. The results showed the same tendency to reduce the measured $M_{\mathrm{W}}$ as GO content increased.

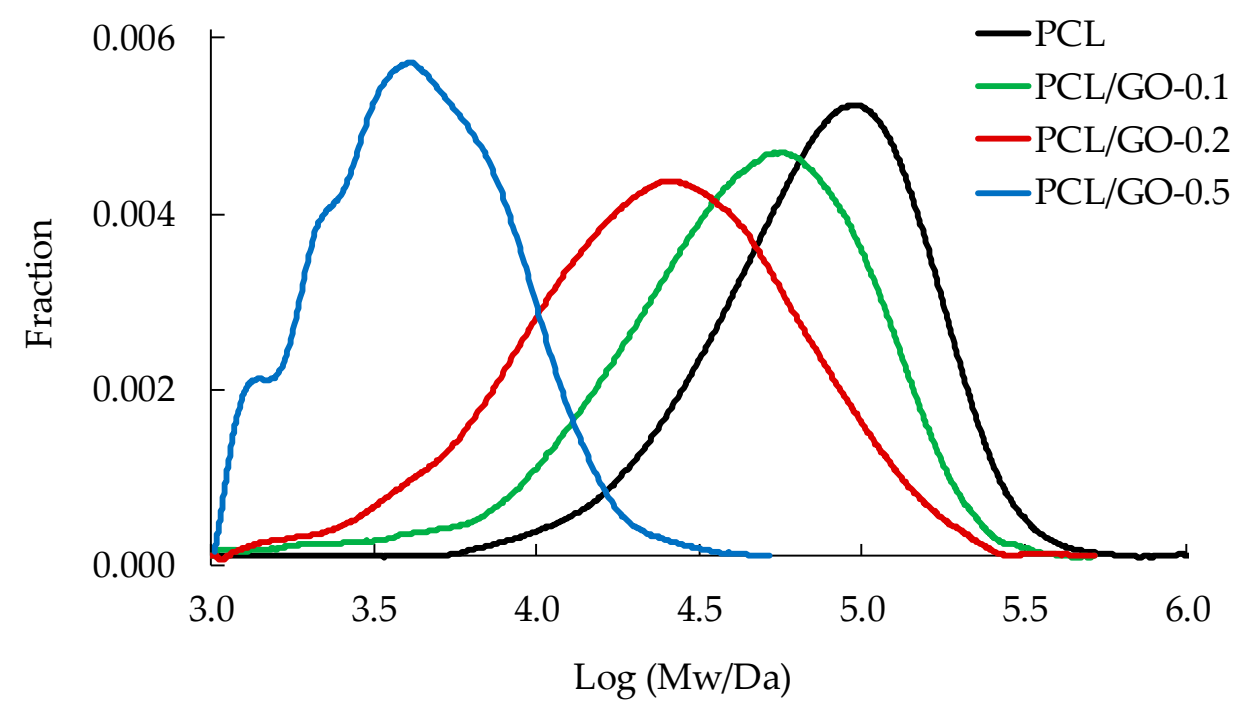

Figure 7. Molecular weight distribution according to GO content (wt\%).

Table 3. $M_{\mathrm{W}}$, and PDI, according to GO content (wt\%).

\begin{tabular}{ccc}
\hline Sample & $\boldsymbol{M}_{\mathbf{w}}$ & PDI \\
\hline PCL & 97095 & 1.63 \\
PCL/GO-0.1 & 61472 & 1.77 \\
PCL/GO-0.2 & 37878 & 2.66 \\
PCL/GO-0.5 & 4436 & 1.59 \\
\hline
\end{tabular}


Many of the processes by which fillers affect polymers are still not fully understood, as has been pointed out in the literature $[47,48]$. The simulation approach in these studies focuses on the ways the filler particles change both the distribution of the end-to-end distances of the polymer chains and the radius of gyration. The extent to which the filler particles can change polymer properties depends significantly on the chain size $R_{\text {pol }}$ vs. particle size $R_{\text {part }}$. In simulations, as long as the energetic filler-polymer interaction is not unrealistically high, the main results are quantitatively governed by the polymer-filler size ratio $\Psi=\frac{R_{\text {pol }}}{R_{\text {part }}}$ finding three different regimes: $\Psi<1, \Psi \approx 1$ and $\Psi>1$ [48]. Some of the simulations find a smaller average radius of gyration $R_{\mathrm{g}}$ when $\Psi \approx 1$ and $\Psi>1$. To our knowledge, no studies have yet been published specifically on the conformations of GO-PCL nanocomposites.

It should be remembered that when analyzing our hybrid samples, the GO flakes varied widely in size, from a few nanometers to microns, as can be seen in Figures 2a and 8. It is also estimated that the end-to-end distance of the dissolved macromolecule should be around $10 \mathrm{~nm}$, and the radius of gyration around $4 \mathrm{~nm}$ (taking into account a Flory's characteristic ratio, $\mathrm{C}_{\infty}$, equal to 5 and an average bond length of $0.149 \mathrm{~nm}$ [46]), so that the size of the GO nanoplates inserted into the macromolecules must be of that order or smaller (Figure 9).
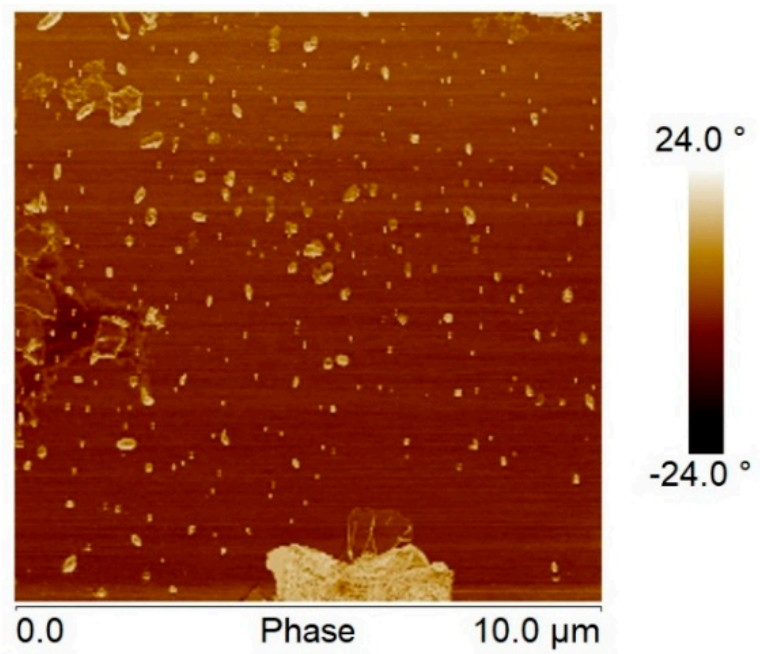

Figure 8. AFM phase image of GO flakes deposited onto mica.

Based on the above-mentioned information and the way in which the GPC works to obtain molecular weight distribution, we tried to find an explanation for the reduction in molecular weight we obtained. It is known that the macromolecular chains of neat PCL are highly compact, especially in the crystalline zones. When the sample is immersed in a good solvent, e.g. THF, the solvent molecules penetrate into the core of the chains and the crystals are dissolved. Under these conditions, a very low-concentration solution passes through the GPC columns and the elution time is as shown in Figure 7 (black profile). On the other hand, when a PCL/GO hybrid is produced, nano-GO flakes are entrapped by macromolecular chains as the solvent evaporates, and different (secondary) interactions between nano-GO and macromolecular chains could take place due to the hydroxyl, carboxyl and epoxy groups present in the GO. When the hybrid is dissolved in THF before the GPC analysis, solvent penetration is counterbalanced by the expansion of the macromolecules, which finds greater resistance due to non-covalent interactions between nano-GO and PCL macromolecules. This could be responsible for the reduced chain dimensions (see Figure 9) [48,49], and therefore longer elution time, and an apparent reduction in the molecular weight as measured by GPC compared to neat PCL. Duan et al. [50] also found that the molecular weight of the PCL matrix decreased with increasing GO content, but they attributed it to the degradation of PCL chains. We find our explanation more plausible than that of Duan et al. since we tested the molecular weight immediately after sample 
preparation and found the same effect. In addition, Duan et al. do not give any data on the molecular weight evolution with time, but only provide the GPC results 50 days after sample preparation.
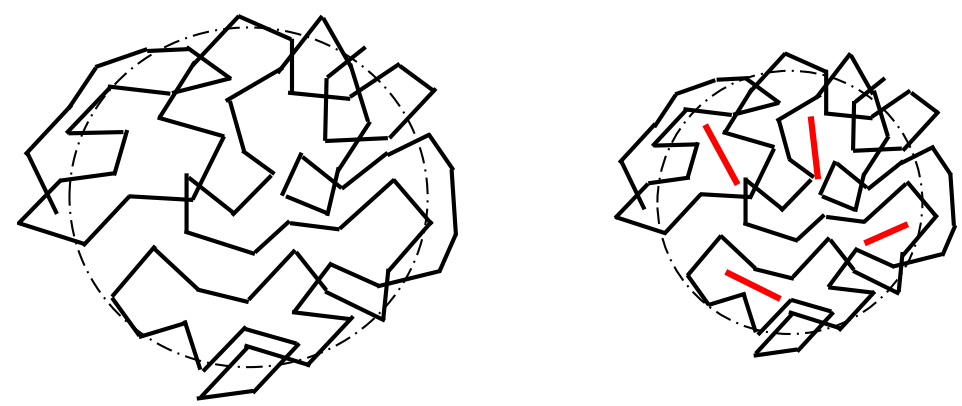

Figure 9. Schematic representation of neat PCL (left) and PCL/GO (right) in a good solvent.

The effect is more pronounced as the percentage of GO increases (see Table 3). The samples containing the highest GO content (see Figure 7) present a complex distribution of molecular weight that seems to consist of three overlapping peaks, indicating the presence of three main distributions, possibly due to molecules with different amounts of GO trapped inside. Polydispersity was found to increase with GO content, except for the hybrid PCL/GO-0.5, which was lower than pure PCL (see Table 3).

\subsection{DSC}

The changes in thermal properties according to GO content were monitored by DSC. Figure 10 shows the DSC curves after removing the thermal history (second heating) and cooling.

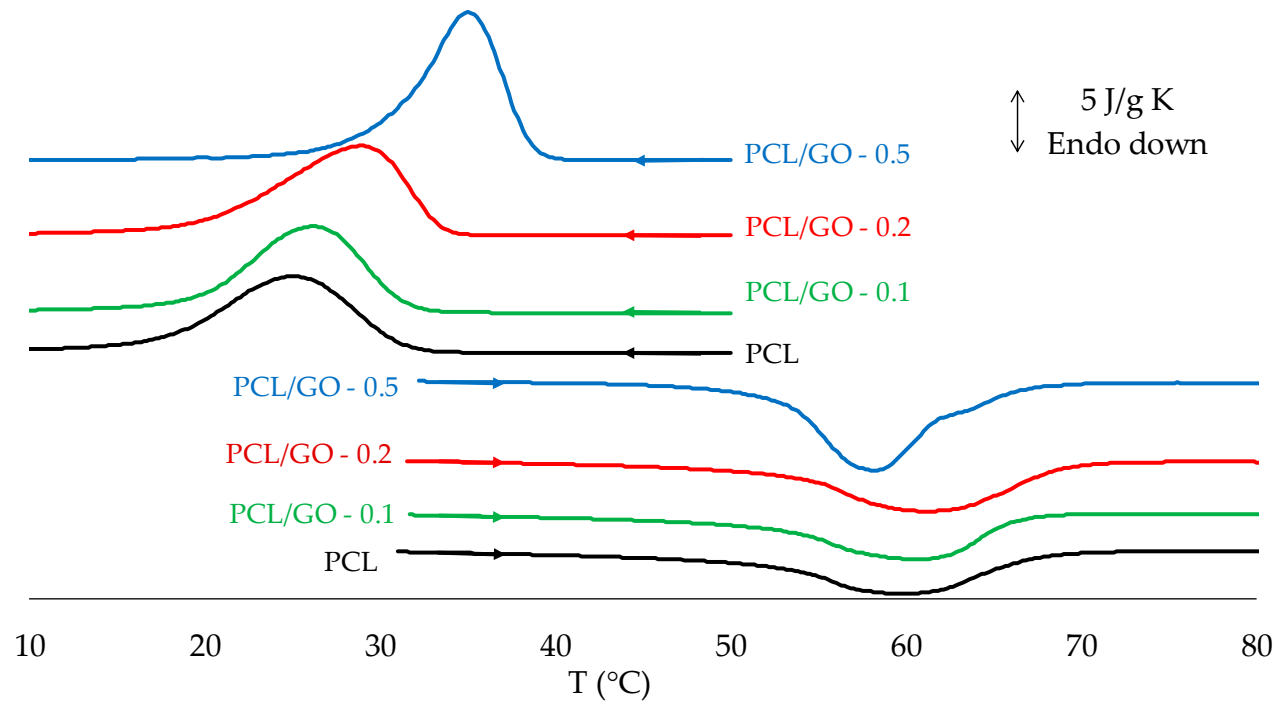

Figure 10. DSC scans for PCL/GO hybrids on cooling and second heating scan (after removing thermal history).

Figure 11 shows crystallinity, $\chi$, (Figure 11a), crystallization peak temperature on cooling, $T_{c}$, and melting peak temperature of the second heating scan, $T_{\mathrm{m}}$ (Figure 11b). It can be seen that crystallinity rose steadily when GO was added, from $39.1 \% \pm 1.8 \%$ for pure PCL to $49.0 \% \pm 3.1 \%$ for PCL/GO-0.5, a remarkable relative increase of $25 \%$, as has been reported in previous studies $[24,28,51]$. The increase in crystallinity with GO can be attributed to the nucleating action of GO sheets in the PCL matrix, as has been observed through POM (Figure 3). Some studies have shown that graphene increases the number of crystallization nucleation sites and thus changes the size and number of the spherulite crystalline regions in polycaprolactone [25]. However, other studies [20,52] have found that crystallinity is reduced when the volume fraction of the fillers is increased, which they attribute to the interfacial 
interactions between GO nanoplatelets and PCL molecular chains. This reduces the chain flexibility and retards the crystallization process. This is not so in our case, since the GO nanosheets could serve as heterogeneous nuclei for PCL crystallization, suggesting that the higher GO content could have raised the crystallinity, as can be seen in (Figure 11a) and was observed by FT-IR. It should also be noted that the samples containing $0.5 \mathrm{wt} \%$, GO have a much broader melting peak (see Figure 10) and there seem to be various peaks combined into one, which suggests that GO nanoplatelets have enlarged the size spectrum of the crystals.

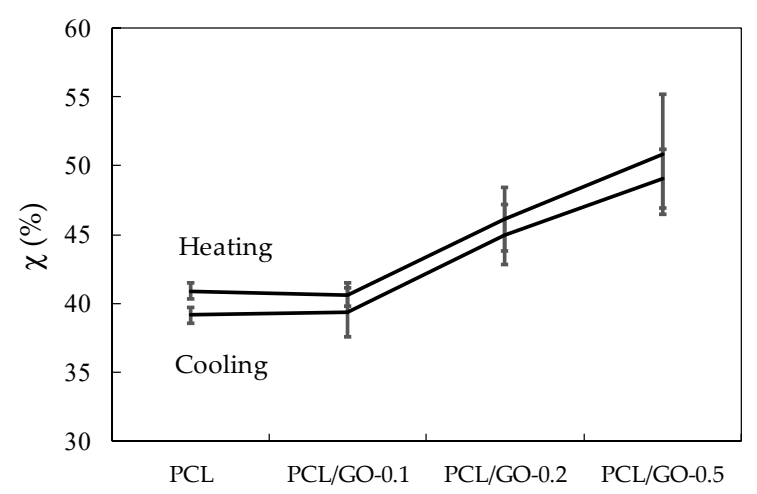

(a)

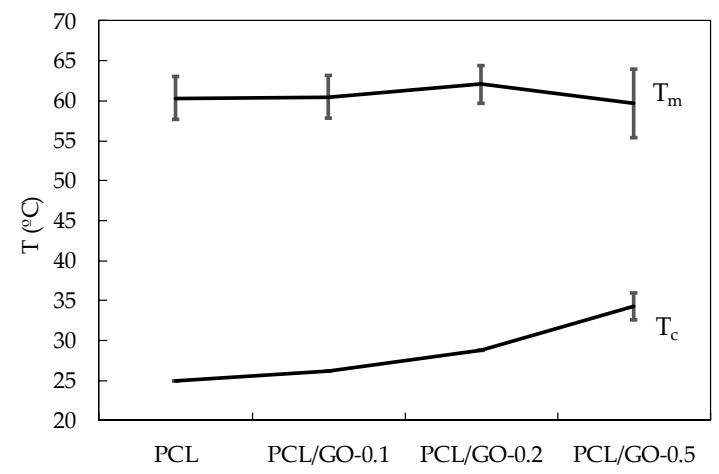

(b)

Figure 11. (a) Effect of $G O$ on hybrid crystallinity. (b) Effect of $G O$ on crystallization and melting temperatures.

DSC data show that adding GO to the PCL structure did not significantly affect the melting point of the hybrids with respect to neat PCL (Figure 11b), as previously reported in [51,53]. The fact that the melting temperature of PCL/GO hybrids is found to be almost unchanged indicates that adding graphene (GO) did not significantly affect the PCL melting behavior. The higher Tc (Figure 11b) when GO was added could mean that the dispersed GO nanosheets acted as efficient nucleating seeds and promoted PCL crystallization, as was seen by POM (Figures 3 and 4).

\section{6. $X R D$}

Figure 12 represents the X-ray diffraction profiles for hybrid samples of PCL/GO. The diffraction pattern shows characteristic PCL peaks at $2 \theta=21.3^{\circ}$ and $23.6^{\circ}$ for pristine PCL, which correspond to (110) and (200) crystallographic planes, respectively [54]. No GO diffraction peaks can be seen for the analyzed PCL/GO samples with different GO loadings, indicating that adding GO has no significant effect on the crystal structure of the PCL matrix [51,55-57] and does not significantly affect the XRD patterns, except for a slight increase in the crystallinity of the PCL/GO hybrids, similar to the effect observed by DSC and FT-IR. The lack of GO diffraction peaks could be attributed to the proper dispersion of GO nanosheets within the PCL matrix, as reported in previous studies $[58,59]$. 


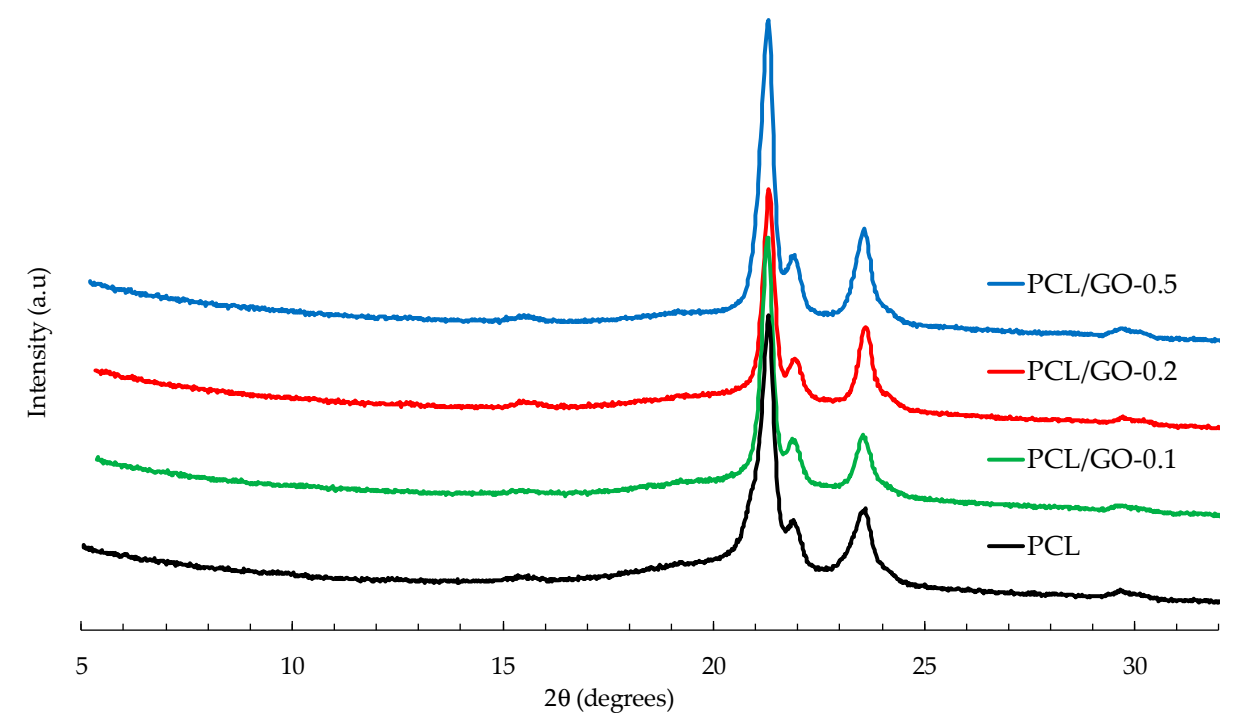

Figure 12. X-ray diffraction of neat PCL and PCL/GO hybrids.

The apparent crystal size was obtained from FWHM by applying Equation (1) to the two main peaks. The results shown in Figure 13 indicate a tendency to larger crystal sizes for 0.1 and $0.2 \mathrm{wt} \%$ GO content and smaller sizes for the composite containing $0.5 \mathrm{wt} \% \mathrm{GO}$. This last result, also found in a previous study [28], can be attributed to the effect of the physical barrier composed of nanoparticles that limits crystallite size.

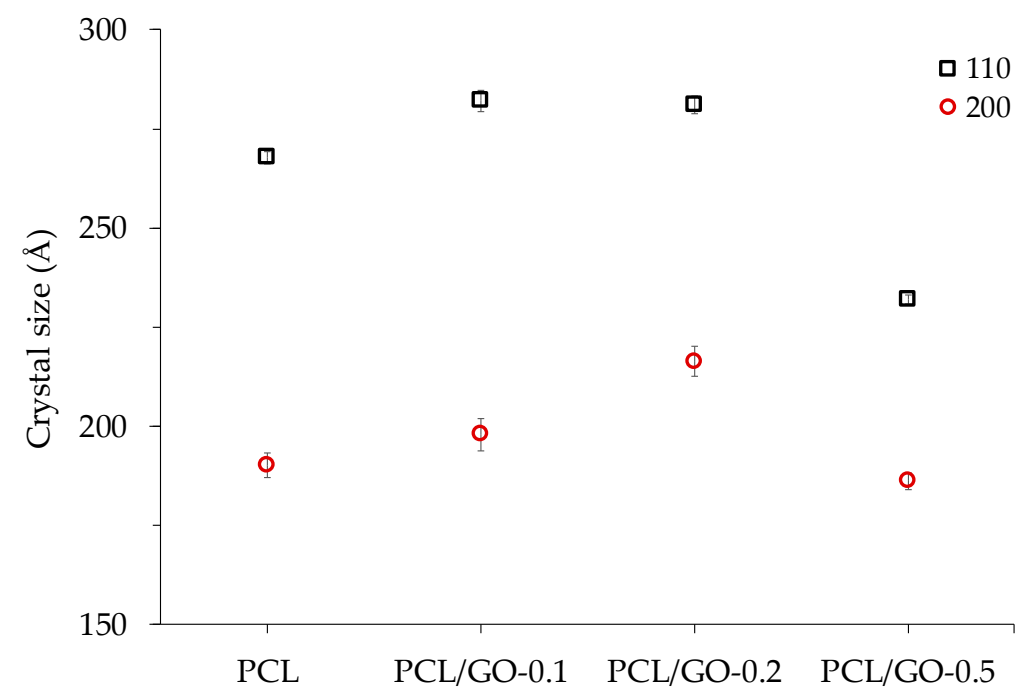

Figure 13. Crystal size of the 110 and 200 planes for different samples.

\subsection{TGA}

TGA was used to analyze composite thermal stability, as can be seen in Figures 14 and 15. Initial decomposition temperature (IDT) ( $5 \%$ weight loss temperature), $T_{\max }$ (max degradation rate temperature), residue at $800^{\circ} \mathrm{C}$ and the theoretical residue obtained by the typical behavior of an ideal mixture are given in Table 4 . This criterion is used to check whether there are any interactions between both components. Equation (2) was used to calculate the theoretical residue of each sample. The GO thermal degradation data were taken from [60].

$$
\frac{\Delta m}{m_{0}}=w_{P C L} \cdot \frac{\Delta m_{P C L}}{m_{0, P C L}}+\left(1-w_{P C L}\right) \cdot \frac{\Delta m_{G O}}{m_{0, G O}}
$$


As observed in Table 4, the hybrids' IDT remains fairly constant with GO contents of up to $0.2 \mathrm{wt} \%$, whereas PCL/GO- 0.5 has an IDT around $30{ }^{\circ} \mathrm{C}$ lower than neat PCL, which could be related to the loss of labile oxygen $\mathrm{GO}$ groups.

The derivative thermogravimetric (DTG) curves (Figure 15) of neat PCL and its nanocomposites were found to undergo single-stage degradation at approximately $413^{\circ} \mathrm{C}$. The maximum degradation rate temperature $\left(T_{\max }\right)$ of PCL and its hybrids did not change, indicating that GO does not affect polymer mass diffusion.

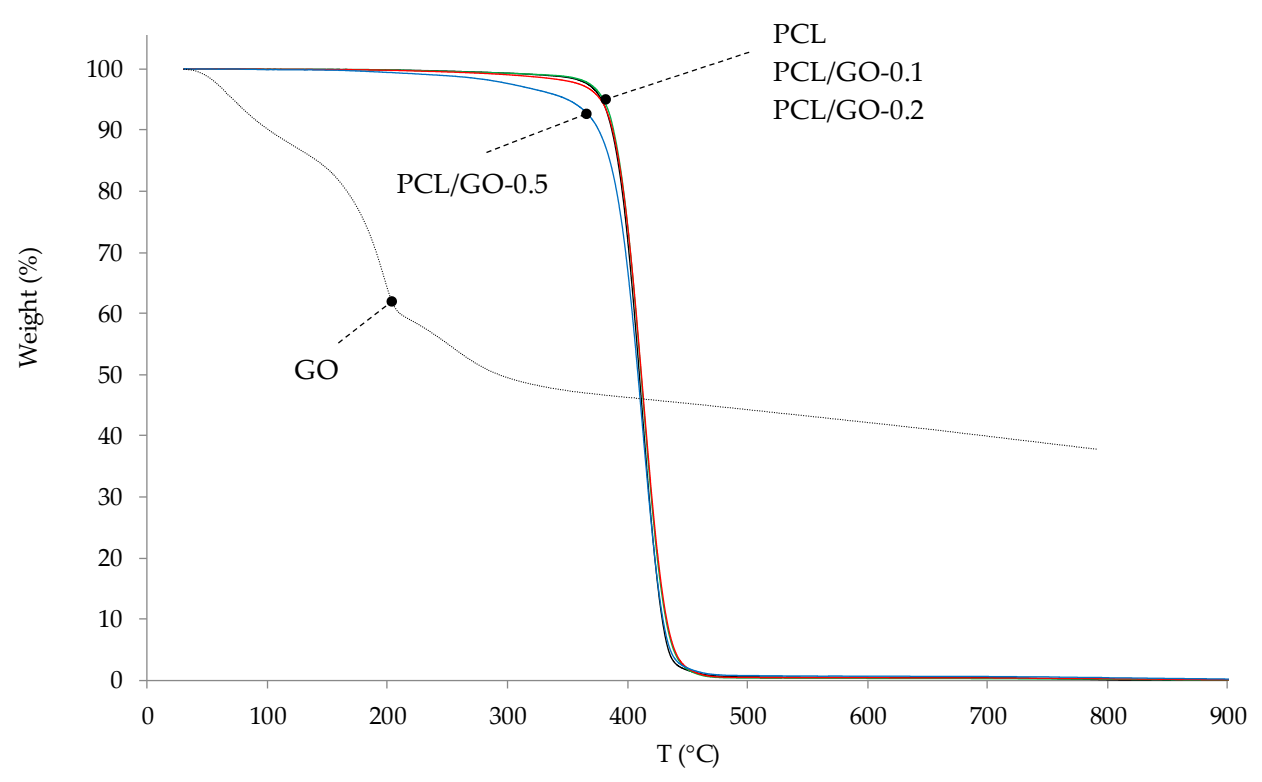

Figure 14. TG plots of PCL and PCL/GO nanocomposites.

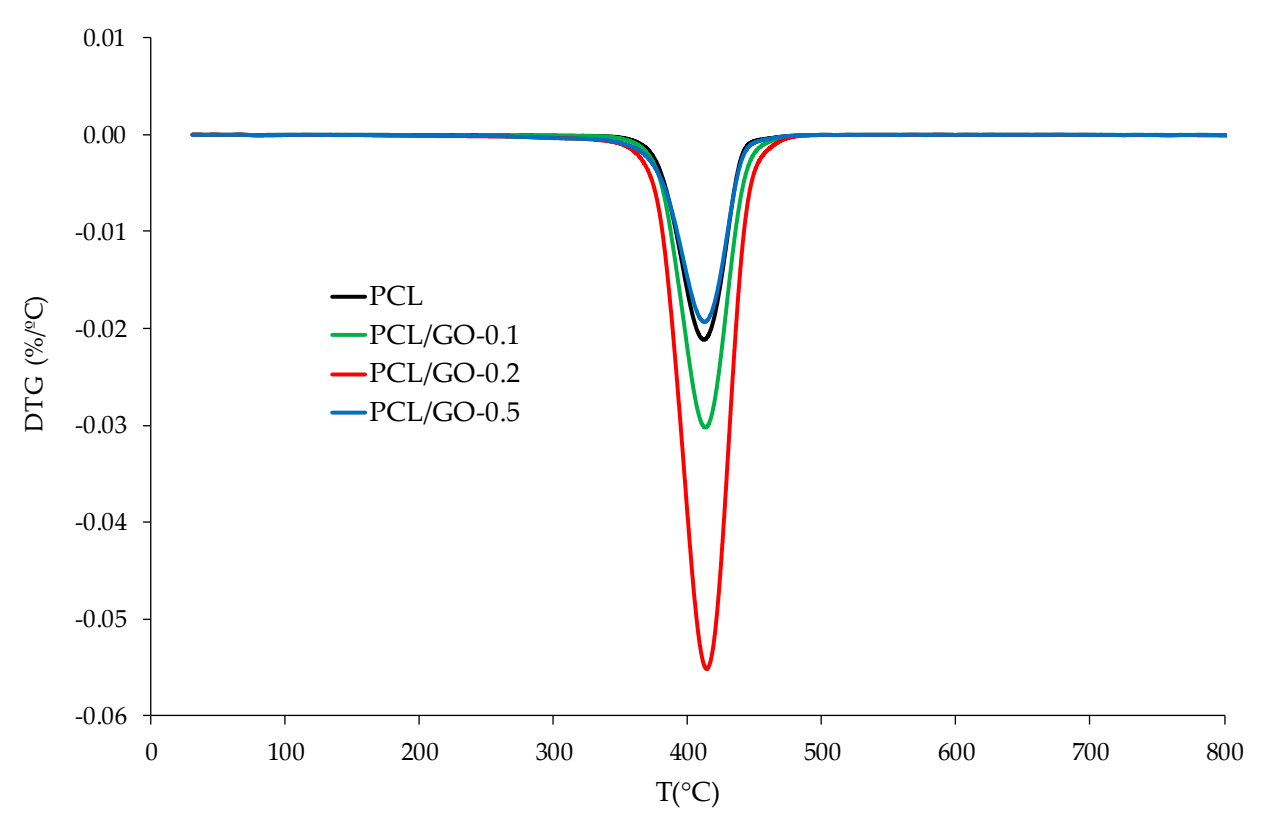

Figure 15. Derivative thermogravimetric (DTG) curves of PCL and its nanocomposites.

Equation (2) predicts that residues at $800{ }^{\circ} \mathrm{C}$ should be $0.14 \%, 0.18 \%$, and $0.29 \%$ for PCL/GO-0.1, PCL/GO-0.2, and PCL/GO-0.5, respectively, although the real residues are higher than those predicted, as can be seen in Table 4 . This agrees with the previous results and indicates an interaction between PCL and GO, probably due to secondary bonds between the polymer chains and GO flakes during solvent evaporation. 
Table 4. Thermal properties of PCL and PCL/GO nanocomposites. Initial decomposition temperature, IDT, temperature of maximum degradation rate, $T_{\max }$, residue measured at $800{ }^{\circ} \mathrm{C}$, and theoretical residue at the same temperature.

\begin{tabular}{ccccc}
\hline Sample & IDT $\left({ }^{\circ} \mathbf{C}\right)$ & $\boldsymbol{T}_{\max }\left({ }^{\circ} \mathbf{C}\right)$ & Residue at $\mathbf{8 0 0}{ }^{\circ} \mathbf{C}(\%)$ & Theoretical Residue at $\mathbf{8 0 0}{ }^{\circ} \mathbf{C}(\%)$ \\
\hline PCL & 378.3 & 412.2 & 0.10 & \\
PCL/GO-0.1 & 379.9 & 413.3 & 0.17 & 0.14 \\
PCL/GO-0.2 & 377.5 & 414.4 & 0.27 & 0.18 \\
PCL/GO-0.5 & 350.2 & 412.6 & 0.45 & 0.29 \\
\hline
\end{tabular}

\subsection{Cellular Viability}

L-929 mouse fibroblasts were used to study PCL and PCL/GO hybrid biocompatibility and the biological response was analyzed by MTT. Figure 16 shows the results after 2 days of culture. The higher absorbance value is in proportion to the number of viable cells. In this study, the cells grown on different materials were compared with polystyrene (negative control), assigning $100 \%$ viability to the latter. PCL, PCL/GO-0.1, and PCL/GO- 0.2 were above $70 \%$ in cell vitality and could be considered non-toxic for the L929 cell line, according to ISO 10993, while the mean value of absorbance for cells in contact with PCL/GO- 0.5 was $58.9 \% \pm 1.9 \%$. Some studies have found that the GO toxic effect on cells depends on the dose used, and that lower GO concentrations affect cell behavior positively [23,61], phenomena which were also found in the present study. The biological response results showed that adding $\mathrm{GO}$ in small doses not only did not restrain cell proliferation but in fact facilitated it. When the GO concentration reached $0.5 \mathrm{wt} \%$, it had adverse effects on cellular behavior, as has also been found by other authors [23].

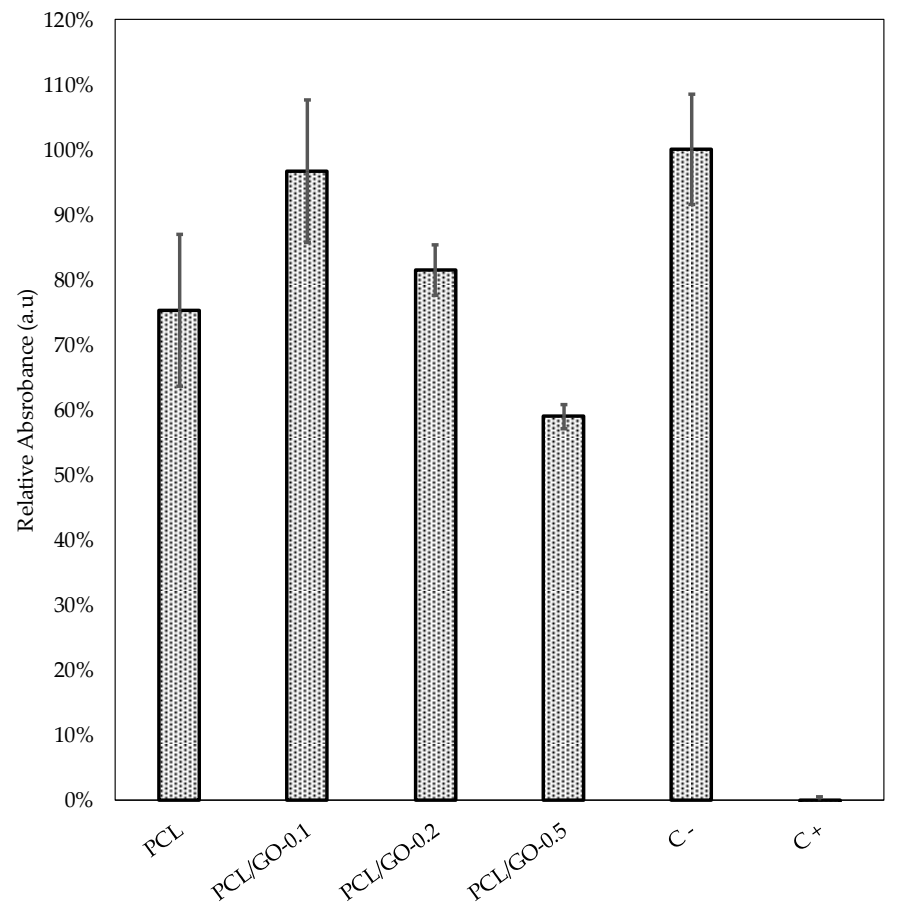

Figure 16. Relative absorbance of the MTT analysis as a function of GO composition. Values are presented as mean \pm SD from six replicates at $48 \mathrm{~h}$. Kruskal-Wallis test shows significant differences between materials $(\mathrm{k}=22.4473 ; \mathrm{p}=0.00016)$. Mann-Whitney U-test showed significant differences between PCL and PCL/GO-0.1 ( $(\mathrm{U}=1 ; \mathrm{p}=0.0083), \mathrm{PCL}$ and $\mathrm{C}-(\mathrm{U}=1 ; \mathrm{p}=0.0083), \mathrm{PCL} / \mathrm{GO}-0.1$ and PCL/GO-0.2 ( $\mathrm{U}=2 ; \mathrm{p}=0.01314), \mathrm{PCL} / \mathrm{GO}-0.1$ and PCL/GO-0.5 $(\mathrm{U}=0 ; \mathrm{p}=0.00512), \mathrm{PCL} / \mathrm{GO}-0.2$ and PCL/GO-0.5 ( $\mathrm{U}=0 ; \mathrm{p}=0.00512), \mathrm{PCL} / \mathrm{GO}-0.2$ and $\mathrm{C}-(\mathrm{U}=2 ; \mathrm{p}=0.01314)$, and PCL/GO-0.5 and C- $(\mathrm{U}=0$; $\mathrm{p}=0.00512)$, whereas no significant differences were found between PCL and PCL/GO-0.2 $((\mathrm{U}=12$; $\mathrm{p}=0.37886), \mathrm{PCL}$ and PCL/GO-0.5 $(\mathrm{U}=6 ; \mathrm{p}=0.06576), \mathrm{PCL} / \mathrm{GO}-0.1$ and $\mathrm{C}-(\mathrm{U}=14 ; \mathrm{p}=0.57548)$. 


\section{Conclusions}

PCL films incorporating GO at different filler contents $(0.1,0.2$ and $0.5 \mathrm{wt} \%)$ were produced by the solution mixing method to advance the understanding of PCL/GO hybrid materials and consider their suitability for use in biomedical applications.

We identified the interactions between the reinforcement, GO, and the matrix, PCL, by means of different techniques. For instance, FT-IR revealed that hydrogen-bonds could have arisen between GO's H-donating groups and PCL's carbonyl groups. POM clearly revealed that the crystallization time is reduced at higher GO concentrations, confirming GO's nucleation effect. The interactions between GO and PCL were also confirmed by the DSC and TGA results. The PCL/GO hybrids were found by DSC to have slightly higher crystallinity and crystallization temperature than neat PCL, which confirms GO's good nucleating effect on PCL crystallization. TGA showed that the real residues were higher than those predicted for an ideal mixture, which again indicates an interaction between the components. The XRD results showed that adding GO does not significantly affect the XRD patterns, except for a slightly higher hybrid crystallinity, similar to the effect observed by DSC.

It should be noted that the GPC data showed a marked reduction of molecular weight with GO content, which can be attributed to the apparently smaller macromolecule size, probably due to the GO nanoflakes being trapped inside the PCL chains and secondary interactions taking place between the GO nanoflakes and polymer chains.

Finally, the cell viability test on L-929 mouse fibroblasts showed that there are statistical differences between PCL/GO-0.1 and the rest of the hybrids, indicating that adding only $0.1 \mathrm{wt} \%$ of GO can improve cellular viability and that the composite shows promise for use in biomedical applications. The next step in this line of research will be to evaluate hydrolytic degradation as a potential candidate for tissue engineering applications.

Author Contributions: Conceptualization, A.J.C.-F., A.V. and I.C-C. Methodology, A.J.C.-F., A.V. and I.C-C; Investigation, A.J.C.-F., A.V., and B.M.; Resources, I.C-C.; Data Curation, A.J.C.-F., A.V.; Writing-Original Draft Preparation, A.J.C.-F., A.V. and I.C-C.; Writing-Review \& Editing, A.J.C.-F., A.V. and I.C-C.; Visualization A.J.C.-F., A.V. and I.C-C..; Supervision, A.J.C.-F., A.V. and I.C-C..; Project Administration, A.V.; Funding Acquisition, A.V.

Acknowledgments: This work was supported by Projects GV/2016/067 of the Generalitat Valenciana and MAT2016-76039-C4-3-R of the Spanish Ministry of Economy and Competitiveness (MINECO). The authors are grateful to M. Monleón-Pradas for his helpful comments and G. Vilariño-Feltrer for his valuable advice on the cell culture experiments. A. Vidaurre would also like to express her gratitude for the support received from CIBER-BBN, an initiative funded by the VI National R\&D\&i Plan 2008-2011, Iniciativa Ingenio 2010, Consolider Program, CIBER Actions financed by the Instituto de Salud Carlos III with assistance from the European Regional Development Fund. SEM, TEM and AFM were conducted by the authors at the Microscopy Service of the Universitat Politècnica de València, whose advice is greatly appreciated.

Conflicts of Interest: The authors declare no conflict of interest.

\section{References}

1. Brodie, B.C. Sur le poids atomique du graphite. Ann. Chim. Phys. 1860, 59, e472.

2. Hummers, W.S.; Offeman, R.E. Preparation of Graphitic Oxide. J. Am. Chem. Soc. 1958, 80, 1339. [CrossRef]

3. Stankovich, S.; Piner, R.D.; Nguyen, S.B.T.; Ruoff, R.S. Synthesis and exfoliation of isocyanate-treated graphene oxide nanoplatelets. Carbon N. Y. 2006, 44, 3342-3347. [CrossRef]

4. Dreyer, D.R.; Park, S.; Bielawski, C.W.; Ruoff, R.S. Graphite oxide. Chem. Soc. Rev. 2010, 39, 228-240. [CrossRef] [PubMed]

5. Konios, D.; Stylianakis, M.M.; Stratakis, E.; Kymakis, E. Dispersion behaviour of graphene oxide and reduced graphene oxide. J. Colloid Interface Sci. 2014, 430, 108-112. [CrossRef] [PubMed]

6. Kuilla, T.; Bhadra, S.; Yao, D.; Kim, N.H.; Bose, S.; Lee, J.H. Recent advances in graphene based polymer composites. Prog. Polym. Sci. 2010, 35, 1350-1375. [CrossRef]

7. Potts, J.R.; Dreyer, D.R.; Bielawski, C.W.; Ruoff, R.S. Graphene-based polymer nanocomposites. Polymer (Guildf) 2011, 52, 5-25. [CrossRef] 
8. $\quad$ Liang, J.; Huang, Y.; Zhang, L.; Wang, Y.; Ma, Y.; Cuo, T.; Chen, Y. Molecular-level dispersion of graphene into poly(vinyl alcohol) and effective reinforcement of their nanocomposites. Adv. Funct. Mater. 2009, 19, 2297-2302. [CrossRef]

9. Han, D.; Yan, L.; Chen, W.; Li, W. Preparation of chitosan/graphene oxide composite film with enhanced mechanical strength in the wet state. Carbohydr. Polym. 2011, 83, 653-658. [CrossRef]

10. Luong, N.D.; Hippi, U.; Korhonen, J.T.; Soininen, A.J.; Ruokolainen, J.; Johansson, L.S.; Do Nam, J.; Sinh, L.H.; Seppälä, J. Enhanced mechanical and electrical properties of polyimide film by graphene sheets via in situ polymerization. Polymer (Guildf) 2011, 52, 5237-5242. [CrossRef]

11. Yang, X.; Tu, Y.; Li, L.; Shang, S.; Tao, X.M. Well-dispersed chitosan/graphene oxide nanocomposites. ACS Appl. Mater. Interfaces 2010, 2, 1707-1713. [CrossRef] [PubMed]

12. Salavagione, H.J.; Gómez, M.A.; Martínez, G. Polymeric modification of graphene through esterification of graphite oxide and poly(vinyl alcohol). Macromolecules 2009, 42, 6331-6334. [CrossRef]

13. $\mathrm{Xu}, \mathrm{Z}$; Gao, C. In situ polymerization approach to graphene-reinforced nylon-6 composites. Macromolecules 2010, 43, 6716-6723. [CrossRef]

14. Kulkarni, D.D.; Choi, I.; Singamaneni, S.S.; Tsukruk, V.V. Graphene oxide - Polyelectrolyte nanomembranes. ACS Nano 2010, 4, 4667-4676. [CrossRef] [PubMed]

15. Bao, C.; Guo, Y.; Song, L.; Hu, Y. Poly(vinyl alcohol) nanocomposites based on graphene and graphite oxide: a comparative investigation of property and mechanism. J. Mater. Chem. 2011, 21, 13942. [CrossRef]

16. Tang, L.-C.; Wan, Y.-J.; Yan, D.; Pei, Y.-B.; Zhao, L.; Li, Y.-B.; Wu, L.-B.; Jiang, J.-X.; Lai, G.-Q. The effect of graphene dispersion on the mechanical properties of graphene/epoxy composites. Carbon N. Y. 2013, 60, 16-27. [CrossRef]

17. Song, Y.S.; Youn, J.R. Influence of dispersion states of carbon nanotubes on physical properties of epoxy nanocomposites. Carbon N. Y. 2005, 43, 1378-1385. [CrossRef]

18. Kim, H.; Miura, Y.; MacOsko, C.W. Graphene/polyurethane nanocomposites for improved gas barrier and electrical conductivity. Chem. Mater. 2010, 22, 3441-3450. [CrossRef]

19. Ahmad, H.; Fan, M.; Hui, D. Graphene oxide incorporated functional materials: A review. Compos. Part B Eng. 2018, 145, 270-280. [CrossRef]

20. Kai, W.; Hirota, Y.; Hua, L.; Yoshio, I. Thermal and Mechanical Properties of a Poly(«-caprolactone)/Graphite Oxide Composite. J. Appl. Polym. Sci. 2008, 107, 1395-1400. [CrossRef]

21. Woodruff, M.A.; Hutmacher, D.W. The return of a forgotten polymer - Polycaprolactone in the 21st century. Prog. Polym. Sci. 2010, 35, 1217-1256. [CrossRef]

22. Wan, C.; Chen, B. Poly( $\varepsilon$-caprolactone)/graphene oxide biocomposites: mechanical properties and bioactivity. Biomed. Mater. 2011, 6, 055010. [CrossRef] [PubMed]

23. Song, J.; Gao, H.; Zhu, G.; Cao, X.; Shi, X.; Wang, Y. The preparation and characterization of polycaprolactone/graphene oxide biocomposite nanofiber scaffolds and their application for directing cell behaviors. Carbon N. Y. 2015, 95, 1039-1050. [CrossRef]

24. Hua, L.; Kai, W.H.; Inoue, Y. Crystallization behavior of poly( $\varepsilon$-caprolactone)/graphite oxide composites. J. Appl. Polym. Sci. 2007, 106, 4225-4232. [CrossRef]

25. Sayyar, S.; Murray, E.; Thompson, B.C.; Gambhir, S.; Officer, D.L.; Wallace, G.G. Covalently linked biocompatible graphene/polycaprolactone composites for tissue engineering. Carbon N. Y. 2013, 52, $296-304$. [CrossRef]

26. Murray, E.; Sayyar, S.; Thompson, B.C.; Gorkin III, R.; Officer, D.L.; Wallace, G.G. A bio-friendly, green route to processable, biocompatible graphene/polymer composites. RSC Adv. 2015, 5, 45284-45290. [CrossRef]

27. Hassanzadeh, S.; Adolfsson, K.H.; Wu, D.; Hakkarainen, M. Supramolecular Assembly of Biobased Graphene Oxide Quantum Dots Controls the Morphology of and Induces Mineralization on Poly( $\varepsilon$-caprolactone) Films. Biomacromolecules 2016, 17, 256-261. [CrossRef]

28. Kumar, S.; Azam, D.; Raj, S.; Kolanthai, E.; Vasu, K.S.; Sood, A.K.; Chatterjee, K. 3D scaffold alters cellular response to graphene in a polymer composite for orthopedic applications. J. Biomed. Mater. Res. B 2016, 104, 732-749. [CrossRef]

29. Shin, S.R.; Li, Y.C.; Jang, H.L.; Khoshakhlagh, P.; Akbari, M.; Nasajpour, A.; Zhang, Y.S.; Tamayol, A.; Khademhosseini, A. Graphene-based materials for tissue engineering. Adv. Drug Deliv. Rev. 2016, 105, 255-274. [CrossRef] 
30. Bianco, A. Graphene: Safe or toxic? the two faces of the medal. Angew. Chemie - Int. Ed. 2013, 52, $4986-4997$. [CrossRef]

31. Zhang, X.; Yin, J.; Peng, C.; Hu, W.; Zhu, Z.; Li, W.; Fan, C.; Huang, Q. Distribution and biocompatibility studies of graphene oxide in mice after intravenous administration. Carbon N. Y. 2011, 49, 986-995. [CrossRef]

32. Jassim, D.A.; Murphy, S.; Newman, L.; Mironov, A.; Prestat, E.; McCaffrey, J.; Menard-Moyon, C.; Rodrigues, A.F.; Bianco, A.; Haigh, S.; et al. The Effects of extensive glomerular filtration of thin graphene oxide sheets on kidney physiology. ACS Nano 2016, 10, 10753-10767. [CrossRef] [PubMed]

33. Santos, C.M.; Mangadlao, J.; Ahmed, F.; Leon, A.; Advincula, R.C.; Rodrigues, D.F. Graphene nanocomposite for biomedical applications: Fabrication, antimicrobial and cytotoxic investigations. Nanotechnology 2012, 23, 395101. [CrossRef] [PubMed]

34. Lim, H.N.; Huang, N.M.; Loo, C.H. Facile preparation of graphene-based chitosan films: Enhanced thermal, mechanical and antibacterial properties. J. Non. Cryst. Solids 2012, 358, 525-530. [CrossRef]

35. Some, S.; Ho, S.M.; Dua, P.; Hwang, E.; Shin, Y.H.; Yoo, H.; Kang, J.S.; Lee, D.K.; Lee, H. Dual functions of highly potent graphene derivative-poly-l-lysine composites to inhibit bacteria and support human cells. ACS Nano 2012, 6, 7151-7161. [CrossRef]

36. Donlan, R.M.; Wu, P.; Grainger, D.W.; Ratner, B.D. An introduction to materials in medicine; Elsevier Academic Press: San Diego, CA, USA, 2004; ISBN 0125824637.

37. Sydlik, S.A.; Jhunjhunwala, S.; Webber, M.J. In Vivo Compatibility of Graphene Oxide with Di ff ering Oxidation States. ACS Nano 2015, 9, 3866-3874. [CrossRef]

38. Crescenzi, V.; Manzini, G.; Calzolari, G.; Borri, C. Thermodynamics of fusion of poly-beta-propiolactone and

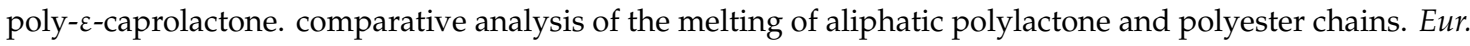
Polym. J. 1972, 8, 449-463. [CrossRef]

39. Klug, H.P.; Alexander, L.E. X-Ray Diffraction Procedures: For Polycrystalline and Amorphous Materials, 2nd ed.; John Wiley \& Sons, Inc.: New York, NY, USA, 1974; pp. 618-708. ISBN 978-0-471-49369-3.

40. Guinier, A. X-Ray Diffraction In Crystals, Imperfect Crystals, and Amorphous Bodies; W.H. Freeman and Company: San Francisco, CA, USA; London, UK, 1963; ISBN 978-0-486-68011-8.

41. Luo, H.; Meng, X.; Cheng, C.; Dong, Z.; Zhang, S.; Li, B. Enzymatic Degradation of Supramolecular Materials Based on Partial Inclusion Complex Formation between r -Cyclodextrin and Poly ( $\varepsilon$-caprolactone ). J. Phys. Chem. B 2010, 114, 4739-4745. [CrossRef]

42. Vidaurre, A.; Meseguer-Duenas, J.M.; Mas-Estelles, J.; Castilla-Cortazar, I. Influence of enzymatic degradation on physical properties of Poly(e-caprolactone) films and sponges. Macromol. Symp. 2008, 269, 38-46. [CrossRef]

43. Honma, T.; Senda, T.; Inoue, Y. Thermal properties and crystallization behaviour of blends of poly( $\varepsilon$-caprolactone) with chitin and chitosan. Polym. Int. 2003, 52, 1839-1846. [CrossRef]

44. Ramazani, S.; Karimi, M. Aligned poly( $\varepsilon$-caprolactone)/graphene oxide and reduced graphene oxide nanocomposite nanofibers: Morphological, mechanical and structural properties. Mater. Sci. Eng. C 2015, 56, 325-334. [CrossRef] [PubMed]

45. Coleman, M.M.; Zarian, J. Fourier-Transform Infrared Studies of Polymer Blends. II. Poly( $\varepsilon$-Caprolactone)Poly(vinyl Chloride) System. J. Polym. Sci. B 1979, 17, 837-850. [CrossRef]

46. Huang, Y.; Xu, Z.; Huang, Y.; Ma, D.; Yang, J.; Mays, J.W. Characterization of Poly(E-Caprolactone) via Size Exclusion Chromatography with Online Right-Angle Laser-Light Scattering and Viscometric Detectors. Int. J. Polym. Anal. Charact. 2003, 8, 383-394. [CrossRef]

47. Sharaf, M.A.; Kloczkowski, A.; Sen, T.Z.; Jacob, K.I.; Mark, J.E. Filler-induced deformations of amorphous polyethylene chains. the effects of the deformations on elastomeric properties, and some comparisons with experiments. Eur. Polym. J. 2006, 42, 796-806. [CrossRef]

48. Nusser, K.; Neueder, S.; Schneider, G.J.; Meyer, M.; Pyckhout-Hintzen, W.; Willner, L.; Radulescu, A.; Richter, D. Conformations of Silica-Poly(ethylene-propylene) Nanocomposites. Macromolecules 2010, 43, 9837-9847. [CrossRef]

49. Vacatello, M. Chain Dimensions in Filled Polymers_ An Intriguing Problem. Macromolecules 2002, 35, 8191-8193. [CrossRef]

50. Duan, T.; Lv, Y.; Xu, H.; Jin, J.; Wang, Z. Structural Effects of Residual Groups of Graphene Oxide on Poly( $\varepsilon$-Caprolactone)/Graphene Oxide Nanocomposite. Crystals 2018, 8, 270. [CrossRef] 
51. Wang, G.S.; Wei, Z.Y.; Sang, L.; Chen, G.Y.; Zhang, W.X.; Dong, X.F.; Qi, M. Morphology, crystallization and mechanical properties of poly(e-caprolactone)/graphene oxide nanocomposites. Chinese J. Polym. Sci. (English Ed.) 2013, 31, 1148-1160.

52. Balkova, R.; Hermanova, S.; Voberkova, S.; Damborsky, P.; Richtera, L.; Omelkova, J.; Jancar, J. Structure and Morphology of Microbial Degraded Poly(E-caprolactone)/Graphite Oxide Composite. J. Polym. Environ. 2014, 22, 190-199. [CrossRef]

53. Yıldırım, S.; Demirtaş, T.T.; Dinçer, C.A.; Yıldız, N.; Karakeçili, A. Preparation of polycaprolactone/graphene oxide scaffolds: A green route combining supercritial CO2 technology and porogen leaching. J. Supercrit. Fluids 2018, 133, 156-162. [CrossRef]

54. Peng, H.; Han, Y.; Liu, T.; Tjiu, W.C.; He, C. Morphology and thermal degradation behavior of highly exfoliated CoAl-layered double hydroxide/polycaprolactone nanocomposites prepared by simple solution intercalation. Thermochim. Acta 2010, 502, 1-7. [CrossRef]

55. Michailidis, M.; Verros, G.D.; Deliyanni, E.A.; Andriotis, E.G.; Achilias, D.S. An experimental and theoretical study of butyl methacrylate in situ radical polymerization kinetics in the presence of graphene oxide nanoadditive. J. Polym. Sci. A 2017, 55, 1433-1441. [CrossRef]

56. Tsagkalias, I.S.; Manios, T.K.; Achilias, D.S. Effect of graphene oxide on the reaction kinetics of methyl methacrylate in situ radical polymerization via the bulk or solution technique. Polymers (Basel) 2017, 9, 432. [CrossRef] [PubMed]

57. Geng, L.-H.; Peng, X.-F.; Jing, X.; Li, L.-W.; Huang, A.; Xu, B.-P.; Chen, B.-Y.; Mi, H.-Y. Investigation of poly(l-lactic acid)/graphene oxide composites crystallization and nanopore foaming behaviors via supercritical carbon dioxide low temperature foaming. J. Mater. Res. 2016, 31, 348-359. [CrossRef]

58. Song, P.; Cao, Z.; Cai, Y.; Zhao, L.; Fang, Z.; Fu, S. Fabrication of exfoliated graphene-based polypropylene nanocomposites with enhanced mechanical and thermal properties. Polymer (Guildf) 2011, 52, 4001-4010. [CrossRef]

59. Bao, C.; Guo, Y.; Song, L.; Kan, Y.; Qian, X.; Hu, Y. In situ preparation of functionalized graphene oxide/epoxy nanocomposites with effective reinforcements. J. Mater. Chem. 2011, 21, 13290. [CrossRef]

60. Sánchez-Correa, F.; Vidaurre-Agut, C.; Serrano-Aroca, A.; Campillo-Fernández, A.J. Poly(2-hydroxyethyl acrylate) hydrogels reinforced with graphene oxide: Remarkable improvement of water diffusion and mechanical properties. J. Appl. Polym. Sci. 2017, 135, 46158. [CrossRef]

61. Liao, K.H.; Lin, Y.S.; MacOsko, C.W.; Haynes, C.L. Cytotoxicity of graphene oxide and graphene in human erythrocytes and skin fibroblasts. ACS Appl. Mater. Interfaces 2011, 3, 2607-2615. [CrossRef] 